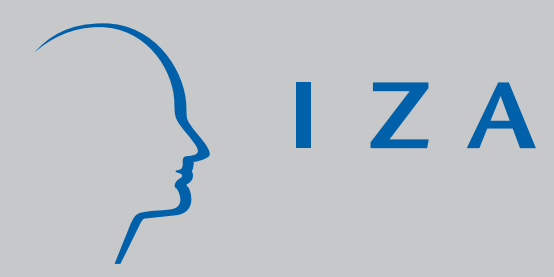

IZA DP No. 3271

Publications:

German Economic Research Institutes on Track

Rolf Ketzler

Klaus F. Zimmermann

December 2007 


\title{
Publications: German Economic Research Institutes on Track
}

\author{
Rolf Ketzler \\ DIW Berlin \\ Klaus F. Zimmermann \\ DIW Berlin, IZA and University of Bonn
}
Discussion Paper No. 3271
December 2007

\author{
IZA \\ P.O. Box 7240 \\ 53072 Bonn \\ Germany \\ Phone: +49-228-3894-0 \\ Fax: +49-228-3894-180 \\ E-mail: iza@iza.org
}

\begin{abstract}
Any opinions expressed here are those of the author(s) and not those of the institute. Research disseminated by IZA may include views on policy, but the institute itself takes no institutional policy positions.

The Institute for the Study of Labor (IZA) in Bonn is a local and virtual international research center and a place of communication between science, politics and business. IZA is an independent nonprofit company supported by Deutsche Post World Net. The center is associated with the University of Bonn and offers a stimulating research environment through its research networks, research support, and visitors and doctoral programs. IZA engages in (i) original and internationally competitive research in all fields of labor economics, (ii) development of policy concepts, and (iii) dissemination of research results and concepts to the interested public.
\end{abstract}

IZA Discussion Papers often represent preliminary work and are circulated to encourage discussion. Citation of such a paper should account for its provisional character. A revised version may be available directly from the author. 


\begin{abstract}

\section{Publications: German Economic Research Institutes on Track}

The request for a strengthening of academic research at the German economic research institutes by the German Science Council more than a decade ago was founded on the crucial insight that sound policy advice - the traditional task of the institutes - can only be guaranteed in the long term if it is based on applied research carried out within the institutes themselves. Based on publications in academic journals, the central criterion of research evaluation, research output has improved remarkably in scope and quality and has involved an ever rising number of scholars within the institutes. It can be considered to be a substantial success of German reform policy, which should be internationally recognized. The present study demonstrates the implications of different methods of filtering and weighting research output to measure publication performance. The ranking of the institutes computed here on the basis of a wide range of alternative concepts provides fairly robust findings. The results are distorted, however, if they are based on a highly selective list of journals as was the case in previous literature.
\end{abstract}

JEL Classification: A11, I 23, L31

Keywords: economic research institutes, research evaluation, publication measurement

Corresponding author:

Klaus F. Zimmermann

DIW Berlin

Mohrenstr. 58

D-10117 Berlin

Germany

E-mail: KZimmermann@diw.de 


\section{$1 \quad$ Introduction}

Applied research, policy advice and service for the public are the main tasks of the publicly financed economic research institutes in Germany. ${ }^{1}$ The unique feature of these institutes is the close connection in their work between research and policy advice, but also the interrelationship between research, policy advice and service, and in contrast to government research bodies their political and academic independence. The institutes have expanded their research activities significantly over the last decade in order to meet the requirements of Leibniz Society (WGL) and the German Science Council ("Wissenschaftsrat") to improve their academic foundation. A strong scientific foundation is of key importance and significance for qualified advice on economic policy according to the German Science Council as outlined in its statement on the economic research institutes (Wissenschaftsrat, 1998). Scientific excellence is also the central criterion of the regular evaluations by independent, external evaluation committees, and a failure to meet the requirements entails the threat of losing public funding. Indeed, only sustained research activities can provide the basis for the high-quality policy advice and the excellent service that will stand up to global competition for the best national economic policies.

Outstanding research is also a necessary prerequisite for the national as well as the international visibility of the economic research institutes. Publications in peer-reviewed journals are generally regarded as evidence of scientific excellence. Recent studies by Steininger and Süßmuth (2005, 2006), Steininger (2007), as well as Keil and Huber (2004, 2007) have assessed the publication activities of the economic research institutes. ${ }^{2}$ The studies by Steininger and Süßmuth (2006) as well as Steininger (2007), which were published exclusively in the Handelsblatt, the leading German daily newspaper for the business community, are indicators of the substantial public interest in the research efforts of the institutes and the increasing competitive climat that they face. These "Research ratings" also recommended by the

\footnotetext{
1 See WGL (1999), p. 25.

2 There has been more research in the recent literature on rankings of university economics departments. See Coupe (2003) and Kalaitzidaki, Mamuneas and Stengos (2003) as examples for worldwide rankings. Beside rakings for U.S. Departments (see for example Thursby (2000)) there are also rankings of departments in Europe by Kalaitzidaki, Mamuneas and Stengos (2003) as well as Germany, Austria and Switzerland by Bommer and Ursprung (1998). Another set of studies focus on the ranking of individual researchers. In general, these studies use a citation based approach for ranking research output. An important recent study was provided by Ursprung and Zimmer (2007), who have evaluated the research output of the 27 best German economists.
} 
German Science Council ${ }^{3}$ document the efforts of the institutes to meet these increased demands for high-quality academic output, and thus also promote effective competition among the institutes.

Frey (2007) has recently attacked the evaluation approach as creating "evaluitis", since this would create the wrong incentives and generate a waste of resources. It would lead to the production of misleading statistics that would aim at proving false success. He suggests competition policy and a proper and highly selective manpower management as alternatives. However, competition among researcher should ensure that the best statistical basis will be established. Evaluation through rankings or through visits of evaluation committees using these rankings wisely will generate the right competitive environment without that no leadership can guarantee the proper development of an institution.

Our study examines the publication activities of Germany’s economic research institutes in the peer-reviewed journals listed in the Social Science Citation Index for the period from 2000 to 2006. Various evaluation criteria are employed to provide a differentiated picture of the institutes' publication output. In addition to analyzing publication output, this study also aims at identifying the intensity with which the researchers employed at the respective institutes contribute to the research. The robustness of the results is examined in analyses using different evaluation criteria. The study aims to measure the extent to which the economic research institutes are meeting the demand to establish strong, broadly based scientific foundations for their policy advisory work and services, and to identify their publication strategies to reach their goals.

\section{Background, Data and methods}

This study deals with the publications in peer-reviewed journals of the German economic research institutes that are members of the Leibniz Society (WGL). These institutes include the German Institute for Economic Research (DIW Berlin), the Kiel Institute for the World Economy (IfW), the ifo Institute for Economic Research (ifo), the Halle Institute for Economic Research (IWH), the Rhineland-Westphalian Institute for Economic Research (RWI) and the Centre for European Economic Research (ZEW), among many more research insti-

\footnotetext{
3 The German Science Council is conducting now for the first time studies itself. The research ratings are currently being done for chemistry and sociology as "pilot disciplines".
} 
tutes from various disciplines. Our study also takes into account publications of the Hamburg World Economic Archive (HWWA), which was a member of the WGL up to the end of 2006, and whose research is now being continued in part by the privately financed Hamburg World Economic Institute (HWWI). ${ }^{4}$ The data used in this study are taken from the annual reports of the institutes or, insofar as not available there, from their websites. ${ }^{5}$

As a tool for measuring publication output, our survey concentrates on the peerreviewed journals listed in the Social Science Citation Index (SSCI), which covers not only economics and all its sub-disciplines but also all related sciences such as sociology, political science, and demography. This breadth is particularly important since institutions like the research institutes that stand in the public spotlight require such a broad scientific basis given the interdisciplinary nature of many different research topics. ${ }^{6}$ The SSCI Index guarantees a high standard of quality in academic journals through strict admission criteria, and thus offers a natural benchmark for studies focusing on the evaluation of publications.

In order to carry out a clearly defined evaluation of the research institutes' publication output, this study only takes into account publications by permanent employees or permanent scholarship holders of the institutes. Publications by so-called (external) fellows and shortterm visiting fellows who list affiliation to the institutes in their publications are as a rule not taken into account, because this work is usually not original research conducted at the institutes. The networks with visiting fellows differ widely in character and function; they mainly provide research impulses for the scientific activities of the institutes. Here, we therefore consider only publications by fellows and visitors with a stay of six months or longer, based on data from employee lists published in the annual reports, on the internet, and in the CVs of the authors. This distinguishes the present study from its predecessors, most of which use the affiliation listed by the authors of the publications in question.

\footnotetext{
${ }^{4}$ Not taken into account here are the Bonn Institute for the Study of Labor (IZA) and the Science Centre Berlin (WZB). The WZB is a multi-disciplinary think tank with a small number of economists. Its research groups can rather be compared with larger endowed chairs at universities with a low level of teaching obligations. The IZA offers only temporary research positions, primarily employs young scientists after their doctorate and is largely an international network of researcher. Both institutions have a lower level of policy advice obligations, although they are committed to economic policy advice. In the analysis presented here, the HWWI is connected to the HWWA, where absolute figures are provided.

${ }^{5}$ In addition, the data were compared and if applicable corrected using the database ISI Web of Knowledge.

6 Institutes such as the DIW Berlin have moreover a high share of researchers with non-economic and interdisciplinary research topics for instance in the departments for Energy, Transportation, and Environment and the Socio-economic Panel Study. Therefore research results are also published e.g. in renowned non-economic journals such as Energy Policy, Electoral Studies, International Migration Review, Journal of Gerontology, Public Opinion Quarterly, Sociological Methods and Research and Transportation Reviews.
} 


\section{Measurement and evaluation of the publications}

Various criteria are available for the bibliometric evaluation of the publication data. These range from simply counting articles, to adjusting data using quality weighting factors, and to conducting an impact analysis of the publications. This study does not limit itself to a single evaluation criterion, but rather employs a variety of indicators and different means of filtering the data to derive comprehensive findings on publication activities. It thus intends to produce more robust and meaningful findings than those of past studies. After all, narrowly defined analytical concepts are of little help to anyone.

Our evaluation of the number of publications in SSCI journals shows an increase in research output across all the institutes in the past few years, and thus confirms the basic results achieved in the previous literature. Fig. 1 exhibits publications in SSCI journals from 2000 to 2006. A significant increase in the published output by the institutes surveyed can be seen, with a rise from just 66 publications at the beginning of the period, as the average in the years 2000 and 2001, to over three times this number for the average of the years 2005 and 2006 with its 241 publications. This trend can also be observed at the level of the individual institutes. The growth was strongest at DIW Berlin, with an increase of 5.5 times the original figure, and weakest at IfW, with an increase of 0.8 times the original figure. It is also clear that DIW Berlin is the institute with the strongest research output based on the absolute number of publications since 2004, and thus has outpaced ZEW, which dominated the field from 2000 to $2003 .^{7}$

The evaluation of the market shares of the absolute research output based on the three periods (2000 to 2001, 2002 to 2004, 2005 to 2006) in Fig. 2 shows that ifo, ZEW and DIW Berlin constantly feature shares of more than 15\%. DIW Berlin is the only institute that succeeded in continuously increasing its publication output over the period of analysis. The falling market share of ZEW is also due to the higher publication figures of the other institutes. The number of SSCI publications by ZEW in 2006 indicates that the institute is following a similar course of development to DIW Berlin. The SSCI publication output of ifo, on the other hand, dropped from 2005 to 2006 (Fig. 1). RWI and IWH showed a moderate increase in the number of publications since 2003. IfW's publication output since 2002 has ranged

\footnotetext{
7 DIW Berlin staff also has a low number of publications in peer-reviewed journals of the Science Citation Index $(\mathrm{SCl})$, the Arts \& Humanities Citation Index $(\mathrm{AHCl})$ and the CompuMath Citation Index (CMCl). These publications are not taken into account here in this study.
} 
from stagnation to a slight decrease. The results on the institutes' market shares are confirmed if co-authorships are also taken into account when measuring the publications by counting only a proportional share of joint publications with scholars from other institutes. ${ }^{8}$

The absolute size of the research output measured by the total number of publications for each institute or the share of the total market are in fact comparably simple measures for research performance. However, they are also important indicators for the visibility of the institutes in academia. There is nothing wrong with absolute measures: The world champion in exports of 2007, Germany, and the likely new champion in 2008, China, is selected according to its absolute size, not in terms of exports divided by population size.

The number of published pages is also sometimes used as an indicator for measuring publication output (see the studies of Steininger and Süßmuth, 2005 and 2006, as well as Steininger, 2007). Fig. 3 shows publication lengths with pro rata consideration of coauthorships for the three periods. The aforementioned results for the institutes with a high share of the research output are robust overall. There was a slight shift in the market shares from DIW Berlin to ZEW and ifo, and IfW overtook the third place from ifo in the middle period. Larger changes can be observed only among the institutes with low market shares. ${ }^{9}$

However, the publication length must generally be considered to be a problematic benchmark for assessing publication output. The printed word density per page varies between the journals, although this distortion can be corrected by adjustment factors. It is more important to recognize that the number of pages is largely regulated by the majority of journals, typically there is a fixed maximum. The exact length of an article is thus an insufficient indicator for its scientific substance. The fact that some journals allow for longer articles does not necessarily mean that these contributions are better. ${ }^{10}$

While an assessment based on the absolute number of published papers provides a good measure of the visibility of the institute, it disregards the fact that the institutes differ widely in size. The absolute number of publications thus does not say anything about produc-

\footnotetext{
8 It is customary to divide a paper by the number of authors. This is a radical procedure as co-operations of scientists are desired particularly in research institutes - also with regard to the range of effect of the research and the policy advice and have a greater innovative potential. Particularly, empirically-oriented scientists work in teams and are thus discriminated compared to colleagues with a focus in theory where working alone is more common. Young scientists could provide better results if this criterion would be waived. However, in this study we follow the traditional procedure.

${ }^{9}$ See also the statements of Keil and Huber (2007), p. 4.

10 The quality is better to assess by the frequency with which the articles are cited.
} 
tivity, that is, publication output in relation to the number of staff members working at the institutes. Hence, Fig. 4 exhibits the annual number of SSCI publications per researcher based on full-time equivalents (FTE). ${ }^{11}$ However, the development of the performance is similar for the relative publication output and for the absolute output.

In the years 2000 and 2001, on average only every tenth full-time equivalent researcher published in an SSCI journal. In the last two years 2005 and 2006, however, almost one of three researchers has been able to publish an article in an SSCI journal. This can be understood as a major success for German science.

DIW Berlin was the only institute to exceed the mark of 0.5 articles per full-time equivalent in the period surveyed, achieving a value of 0.68 in 2006. Based on this indicator, HWWA appears in a much better position over the period surveyed than based on the absolute research output.

A comparison of the market shares of relative and absolute research output shows that there are several clear changes in the publication ranking. The three best-placed (and large) institutes (DIW Berlin, ifo and ZEW) decreased in significance as compared to IfW, RWI, IWH and HWWA (compare Fig. 5 with Fig. 2). At HWWA and IfW, we see a higher relative research output than at DIW Berlin and ifo for the first two periods. ${ }^{12}$ The decision to remove HWWA from the list of publicly funded service institutions with the task of performing research has apparently had no effect on this institute's progress in research productivity.

Smaller shifts of the ranking in Fig. 5 are produced if other indicators are used for measuring the relative research output. The consideration of co-authorships assessed based on the number of publications as well as the publication length consistently leads to a fall in the market share of DIW Berlin. When the number of pages per full-time equivalent is weighted by institution, DIW Berlin maintains its position in the ranking only in the third period. In this case, ifo, ZEW, IfW and HWWA occupy better positions than before (see Fig. 6).

\footnotetext{
11 The data concerning the full-time equivalents of the institutes for the period from 2000 to 2005 were made available to the authors through the friendly support of Mr Steininger. The data for 2006 are estimates, which were forecast based on the ratio of the number of scientists to the number of full-time equivalents in 2005 by using the data concerning the number of scientists for 2006 .

12 HWWI can show a publication output of 0.63 articles per full-time equivalent for 2006 (see Fig. 4). Owing to the structural change associated with the transition from HWWA to HWWI, the relative publication output of 2006 can no longer be compared with the previous values for the years 2000 to 2005 and is therefore disregarded.
} 


\section{$4 \quad$ Robustness of the results with another selection of journals}

The results of the publication ranking are based on various assumptions. In their survey, Steininger and Süßmuth (2006) identify the eclectic selection of research institutes used in various surveys as a decisive factor for the research rankings produced. The following section shows, however, that the selection of journals used in the underlying journal reference list has a decisive influence on the rankings of the economic research institutes. We thus adopt the approach employed by Steininger and Süßmuth to establish full comparability of the consequences of this selection when compared with our findings so far.

The selection of journals of Steininger and Süßmuth is based on the results of the study of Bräuninger and Haucap (2001), which uses a survey among members of the Verein für Socialpolitik, the German Economic Association. In the study by Steininger (2007) out of a total of 150 journals from Bräuninger and Haucap’s list, 64 were ultimately included, 51 of which are SSCI journals. However, non-peer-reviewed journals such as "Wirtschaftsdienst" or "Wirtschaftswissenschaftliches Studium" were included as well. In addition, important research fields such as energy and environmental economics, demography and related sciences such as sociology are not covered by journals on the Steininger list. ${ }^{13}$ Steininger and Süßmuth (2006) also consider the differing scientific quality of the publications by using weighting factors when setting up the publication ranking, which are also based on the survey results of Bräuninger and Haucap (2001). These weightings essentially reflect the views of German economics professors regarding these journals’ scientific relevance and importance for their own work as well. Such a weighting appears questionable, at least if one intends to evaluate the publication output of research institutes that are obligated to provide advice on economic Research output in non-economics or interdisciplinary journals is completely disregarded, ignoring most of the scientific output of two out of seven departments at DIW Berlin. In order to achieve comparability, one would at least have to disregard these departments in the calculations for the full-time equivalents of the institute.

\footnotetext{
13 The SSCI Index currently covers 210 professional journals in economics, 105 in sociology, 99 in political science, and 21 in demography. The Steininger list is thus deliberately selective, this is part of a specific quality filter, which however in our opinion does not meet international standards.
} 
The results of the publication ranking using the methods of Steininger and Süßmuth (2006) deviate in some cases substantially from the results cited above. ${ }^{14}$ Based on the journal reference list used with Steininger (2007) with consideration of the quality weightings Fig. 7 shows a fall in the research output over the three periods at ZEW and IfW as well as an increase in the research output of DIW Berlin and ifo. The ifo Institute achieves the highest market share in the last period, followed by DIW Berlin and ZEW. If the quality-weighted number of published pages is used as an indicator taking into account co-authorships, however, ZEW dominates the publication ranking across all periods (Fig. 8). The market shares of the publication output by DIW Berlin fall clearly behind ifo, ZEW and also IfW in the middle range of the ranking.

The analysis of the relative research output (productivity) in line with Steininger (2007) provides a similar picture. The ifo Institute shows the highest market share of research output for each of the same indicators weighted with the number of full-time equivalents for the last period. Based on the number of published pages per full-time equivalent, the ifo institute increased its research output threefold from 9 to $27 \%$ from the first to the last period. DIW Berlin was able to moderately increase productivity on a low level (Fig. 9 and 10).

The use of the Steininger list for publication evaluation has a substantial influence on the publication ranking as compared to the SSCI list. This influence can be seen most clearly based on the example of the ifo institute. Whereas based on the SSCI journal list ifo shows only a consistently slight increase in research output for the various indicators but no dominating position within the ranking, based on the Steininger data, it shows the highest growth rates in research output as well as the highest relative research output in the years 2005 and 2006. The differences to the SSCI evaluation are most striking, if the relative publication length is used as an indicator. The leading position occupied by DIW Berlin in the years 2005 and 2006 based on the SSCI data is not reproduced when using the Steininger list. In addition, a sharper fall in the research output of IfW can be observed in the latter case. The research output of ZEW, on the other hand, proves to be relatively robust to both lists.

The different results of the publication evaluations allow the conclusion that the shifts within the publication ranking are dependent on the specific selection of journals in the refer-

\footnotetext{
14 As opposed to the procedure of Steininger and Süßmuth (2006) as well as Steininger (2007) no adjustment is made here in this study to adjust for the affiliation of a person with different academic institutions. We allocate everbody to the institution with the major employment position.
} 
ence list of Steininger and Süßmuth (2006) and in particular of Steininger (2007). The survey used to compile a journal list and to create quality weights was conducted mainly among German-speaking economists affiliated with universities, whose focus is primarily economic theory. The Steininger list thus does not necessarily include journals relevant for the task of the economic research institutes, whose research focus is primarily empirical. It also has a bias against non-economics and interdisciplinary journals. The Steininger list therefore appears less suitable for the objective aim of this study to survey the implications of different measurement concepts as compared with the more comprehensive SSCI list. ${ }^{15}$ When using the Steininger list, one should at least adjust the full-time equivalents by those departments at the institutes that are not covered with their research areas by the listed journals in order to guarantee a certain degree of comparability.

\section{$5 \quad$ Quality analysis}

The quality aspect is examined in more detail below, also within the framework of the SSCI data. In addition to weighting the publication data by the number of co-authors as well as within the framework of the comparison of productivity by full-time equivalents, we also carry out a quality weighting of SSCI publications in order to analyse in more detail how a quality weighting based on Steininger (2007) influences the publication ranking. Here, for the quality weighting of the SSCI publications, in contrast to Steininger and Süßmuth (2005, 2006), we use the impact factors generally employed in the literature, which are derived from the journals' citation frequency. ${ }^{16}$

The presentation in Fig. 11 shows that when taking into consideration the quality aspect-as in the simple analysis of the number of SSCI publications-ZEW shows the highest market share for the first two periods and DIW Berlin for the last period. Different trends can be observed between the individual periods at the ifo institute, IfW, and the HWWA. It is interesting that the developments at ifo and IfW are very similar here to results based on the Steininger data. However, the market shares of the research output of these two institutes are

\footnotetext{
15 See also the arguments of Keil and Huber (2004), p. 364.

16 See Neary et al. (2003), p. 1244. No impact factors are available for a few journals. These journals are not taken into account in the further evaluation of the publications.
} 
now far smaller. This fact indicates that the relatively low number of journals in the Steininger list and its choice-based bias clearly has an affect on the level of the market shares assessed and thus on the research ranking compared with the SSCI Index. Comparable results are obtained if an adjustment is also made with respect to the number of co-authors.

The presumed division between institutes with strong research output and institutes with weak research output measured in market shares diminishes steadily if the institutes' productivity is analyzed based on the quality-weighted relative research output in relation to full-time equivalents. Here, as with the previous analysis, this produces decreasing market shares at DIW Berlin, ifo, and ZEW and increasing shares at the other institutes (Fig. 12). However, DIW Berlin is still in the lead in the last period and more up-front in comparison with the ZEW.

The publication ranking of the institution-weighted numbers of pages in SSCI publications taking into account the quality aspect but not adjusting for staff size (Fig. 13) only leads to smaller changes in the order compared with Fig. 3. Again, DIW Berlin replaces ZEW in the leading position in the last period.

The relevant evaluation of the relative publication output assessed in numbers of pages (Fig. 14) also supplies comparable results as the evaluation without consideration of the quality aspect in Fig. 6. A higher market share of IfW can be observed here for the years 2000 to 2004. However, again DIW Berlin is taking the clearly leading position in the last period.

\section{$6 \quad$ Distribution within the institutes}

Analyses of publication achievements usually deal exclusively with the evaluation of the overall research output, but not with the internal distribution of this research. However, for an institution-related assessment of research and policy advice, the question of how broad the research base is among the employees is of central importance, since advice (and service) should be based on research in each individual case. Therefore, we surveyed for the first time how the publication output is distributed over the scientists employed at the respective institutes. Steininger and Süßmuth $(2005,2006)$ also note that high-quality economic policy advice requires high-quality research, as demonstrated by a high level of publication activities at the respective institutes. 
The scientific foundation necessary for the institutes' policy advisory work can only be ensured through the involvement of as many "heads" as possible in the preparation of research publications. A concentration of publications among a few employees with a high level of research output is not sufficient to guarantee the provision of high-quality economic policy advice throughout an institution.

The distribution of the publication output among individual researchers in the institutes can be illustrated using the concept of the Lorenz curve. Here, the Lorenz curve states the percentage of researchers who contributed to a certain percentage of publication output. ${ }^{17}$ The publication data are initially adjusted by external co-authorships and subsequently ordered according to the number of publications for the construction of the Lorenz curve.

Due to the low numbers of publications in the first few years of the period surveyed, the analysis concentrates on the years 2004 and 2006. Fig. 15 shows that no more than 25\% of the researchers (assessed in full-time equivalents) contributed directly to the publication output in any of the institutes in 2004. The Lorenz curves of the institutes are comparably close to each other. The research output was concentrated heavily among just a few researchers at HWWA and IWH in 2004. The broadest distribution of publications among researchers within an institute was seen at DIW Berlin, closely followed by IfW.

The publication distribution changed considerably in 2006 (Fig. 16). The increasing distance between the Lorenz curves illustrates the different developments underway in the research institutes. In particular, DIW Berlin and ZEW show a far higher share of researchers involved in publications in peer-reviewed journals: at DIW Berlin, almost every second researcher was involved in an SSCI journal publication in 2006. In the last two years, the IfW was unable to maintain his performance and showed a higher concentration of research in 2006 than two years before. In 2006, the strongest concentration of publication activities in peer-reviewed journals was observed at the ifo Institute, where just under $20 \%$ of the researchers contributed to these publications.

\footnotetext{
17 With an equally distributed publication output of all researchers the Lorenz curve is identical with the bisecting line. The greater on the other hand the area between the angle bisector and the Lorenz curve the more unequal is the distribution of the publication output within the institute.
} 


\section{$7 \quad$ Conclusions}

A significant increase can be observed in the German economic research institutes' publications in peer-reviewed journals since the year 2000. DIW Berlin has made the strongest contribution to this development and has achieved the highest visibility based on the absolute number of peer-reviewed publications. The analysis of SSCI publication data, also using further indicators, in particular controlling for academic quality, leads to shifts in the market shares away from those institutes with high publication output. The ranking of the institutes nevertheless appears to be robust. The differences in the market shares between the institutes are much smaller with the relative publication evaluation, which is an indicator for the productivity of the researchers at the institutes.

The analysis shows that in evaluating publication activities, both the number and the length of publications as well as the selection of the journal reference list have a significant influence on the ranking. In those cases, major changes in the publication ranking result. The selection of journals leads to distortions in the measurement of research output if the list does not comprise important research fields, as with the list compiled by Steininger and Süßmuth (2005, 2006) and Steininger (2007). The SSCI list is the more suitable reference list for the aim of such an analysis: it appears more appropriate in the context of the tasks assigned to the economic research institutes and most useful for their assessment through a research ranking.

The results found for the distribution of publication efforts in connection with the further results of this study indicate different publication strategies within the institutes. A higher concentration of publication activities among a low number of researchers can be observed at the ifo institute and at the IfW, which are more oriented towards university research benchmarks. On the other hand, the publications of DIW Berlin and ZEW are distributed across a significantly greater share of scientists, who have published rather articles in the broad majority of peer-reviewed journals.

The evaluation of the distribution of publications shows that the institutes need to increase their efforts to ensure a solid academic foundation for their economic policy advice across the full spectrum of research staff. In the year 2006, ZEW and DIW Berlin have already achieved considerable progress for this objective. 
There is, however, a quantity-quality trade-off: If only the more gifted scientists are allowed to publish in an institute, the share of high quality journals that can be reached is higher. Hence, if the objective is to bring most research staff to regular publications as is the objective now, one has to accept a decling share of high quality journals with a rising total number of publications, at least in the long run. Only in the short run, one may be able to simultaneously increase quality and quantity by qualifying current staff and employing better people. 


\section{References}

Bommer, R., Ursprung, H. (1998) Spieglein, Spieglein an der Wand. Eine publikationsanalytische Erfassung der Forschungsleistungen volkswirtschaftlicher Fachbereiche in Deutschland, Österreich und der Schweiz. Zeitschrift für Wirtschafts- und Sozialwissenschaften 118, 1-28

Frey, B. (2007) Evaluierungen, Evaluierungen ... Evaluitis. Perspektiven der Wirtschaftspolitik, 8 (3), 207-220

Bräuninger, M., Haucap, J. (2001) Was Ökonomen lesen und schätzen: Ergebnisse einer Umfrage. Perspektiven der Wirtschaftspolitik, 2 (2), 85-210

Coupe, T. (2003) Revealed Performances: Worldwide Rankings of Economists and Economics Departments, 1990-2000. Journal of the European Economic Association 1(6), 1309-1345

Huber, P., Keil, A. (2007) Ach wie gut, dass niemand weiß ...? Anmerkungen zur Methodenwahl bei Institutsrankings. WIFO Working Papers 287

Kalaitzidakis, P., Mamuneas, T., Stengos, T. (2003) Rankings of Academic Journals and Institutions in Economics. Journal of the European Economic Association 1(6), 1346-1366

Keil, A., Huber, P. (2004) „Wo die Luft dünn wird...“ - Zur Publikationstätigkeit der Wirtschaftsforschungsinstitute Österreichs und Deutschlands. Perspektiven der Wirtschaftspolitik, 5(3), 363375

Neary, J., Mirrlees, J, Tirole, J. (2003) Evaluating Economics Research in Europe: An Introduction. Journal of the European Economic Association 1(6), 1239-1249

Steininger, M., Süßmuth, B. (2005) Elfenbeinligen und ihre Erfassung: Ein Kommentar und eine neuerliche Messung der Publikationstätigkeit der Wirtschaftsforschungsinstitute im deutschsprachigen Raum: 1989-2003. Perspektiven der Wirtschaftspolitik, 6 (3), 409-420

Steininger, M., Süßmuth, B. (2006) Publish or Perish? Die Publikationsaktivitäten deutscher Wirtschaftsforschungsinstitute: 1997-2005, (Version: 14.02.2006)

Steininger, M. (2007) Denkfabriken im Vergleich: Die Publikationsaktivität deutscher Wirtschaftsforschungsinstitute 2000-2006, (Version: 09.07.2007)

Thursby, J. (2000) What Do We Say about Ourselves and What Does It Mean? Yet Another Look at Economics Department Research. Journal of Economic Literature, 38, 383-404

Ursprung, H., Zimmer, M. (2007) Who is the „Platz-Hirsch“ of the German Economics Profession? Jahrbücher für Nationalökonomie und Statistik, 227/2, 187-208

Wissenschaftsrat (1998) Stellungnahme zu den Wirtschaftsforschungsinstituten der Blauen Liste in den alten Ländern - Allgemeine Gesichtspunkte. In: Stellungnahme zu den Instituten der Blauen Liste, Bd. III, Köln

WGL (1999) Stellung und Bedeutung der Wissenschaftsgemeinschaft Gottfried Wilhelm Leibniz e. V. in der deutschen Forschungslandschaft, 1. Memorandum, Dresden/Bonn 
Fig. 1

Number of SCCI publications

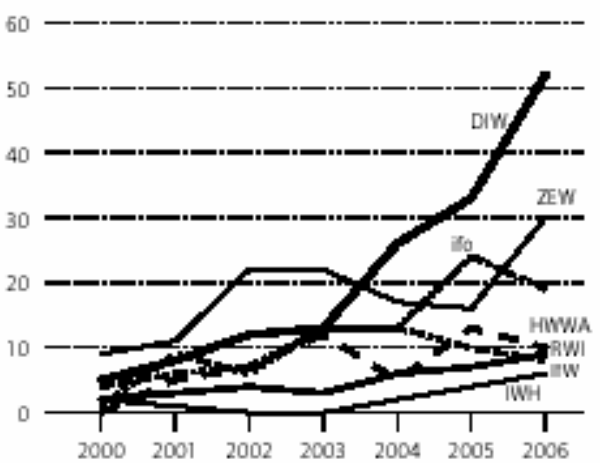

Sources: Annual reports of the institutes; calculations of DIW Berlin.

DIW Berlin 2007

Fig. 2

Number of publications

Market share in \%

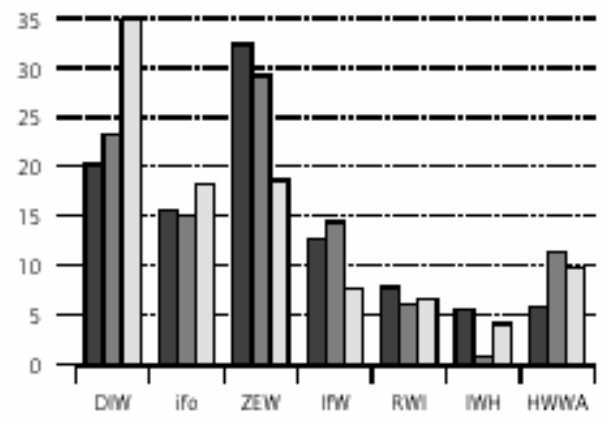

$\square$ 2000-2001 2002-2004 $\square$ 2005-2006

Sources: Annual reports of the institutes; calculations of DIW Berlin.

DIW Berlin 2007 
Fig. 3

Number of pages weighted by institutions

in $\mathrm{SSCl}$ publications

Market share in \%

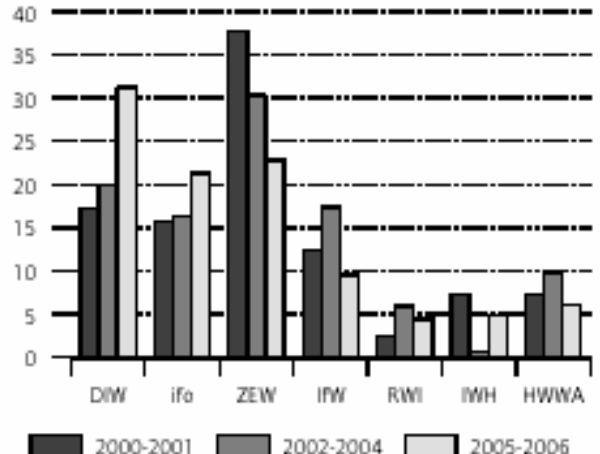

Sources: Annual reports of the institutes; calculations of DIW Berlin.

DIW Berlin 2007

Fig. 4

Number of SSCI publications per full-time equivalent

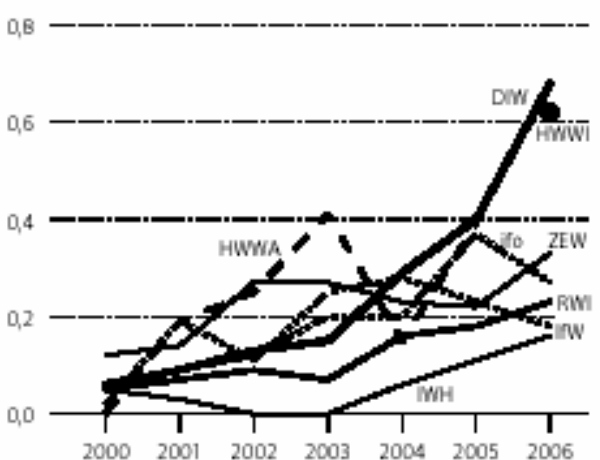

Sources: Annual reports of the institutes; calculations DIW Berlin.

DIW Berlin 2007 
Fig. 5

Number of SSCI publications per full-time equivalent Market share in \%

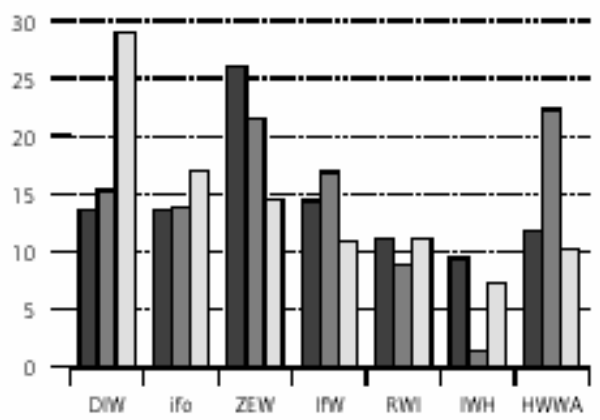

$\square$ 2000-2001 20002-2004 $\square$ 2005-2006

Sources: Annual reports of the institutes; calculations of DIW Berlin.

DIW Berlin 2007

Fig. 6

Number of SSCI publications per full-time equivalent weighted by institutions

Market share in \%

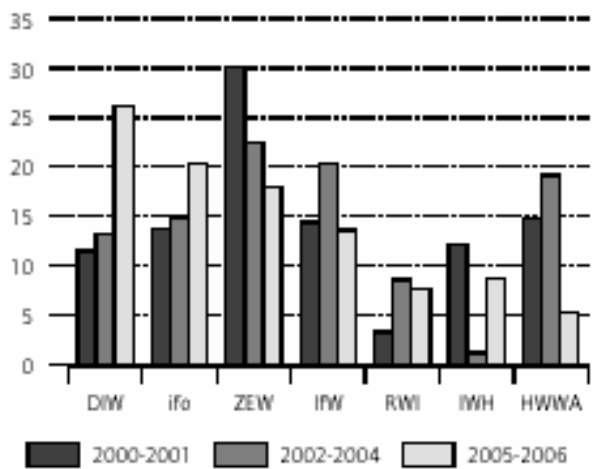

Sources: Annual reports of the institutes; calculations of DIW Berlin.

DIW Berlin 2007 
Fig. 7

Number of publications (Steininger list) Market share in \%

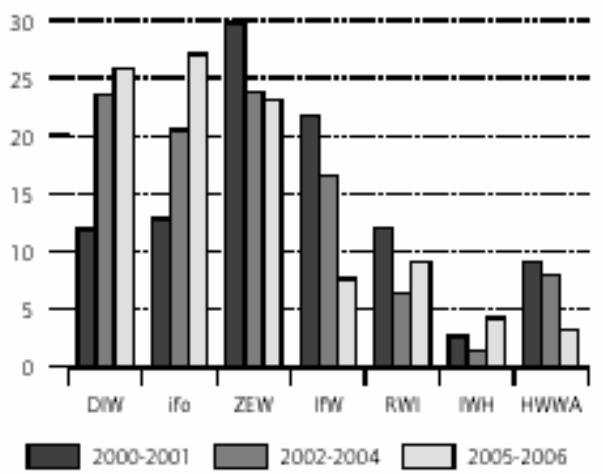

Sources: Annual reports of the institutes; calculations of DIW Berlin.

DIW Berlin 2007

Fig. 8

Number of published pages (Steininger list) Market share in \%

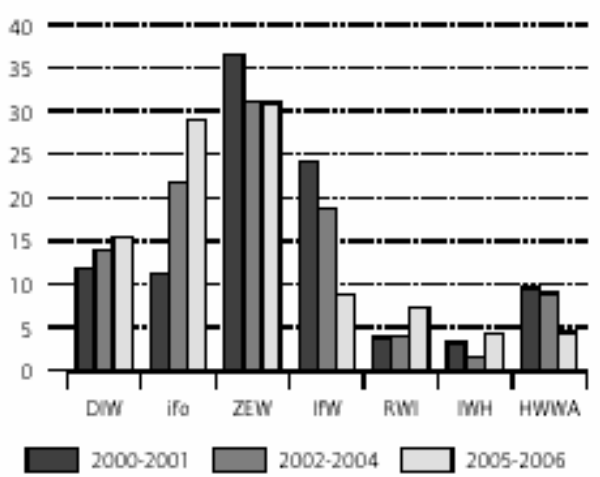

Sources: Annual reports of the instiutes; calculations of DIW Berlin.

DIW Berlin 2007 
Fig. 9

Number of publications per full-time equivalent (Steininger list)

Market share in \%

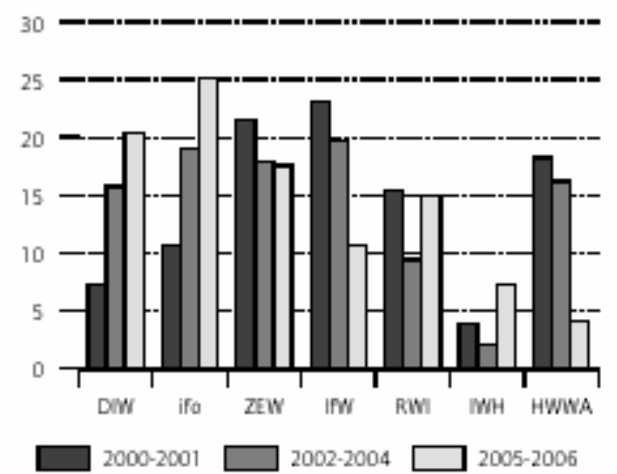

Sources: Annual reports of the institutes; calculations of DIW Berlin.

DIW Berlin 2007

Fig. 10

Number of published pages per full-time equivalent (Steininger list)

Market share in \%

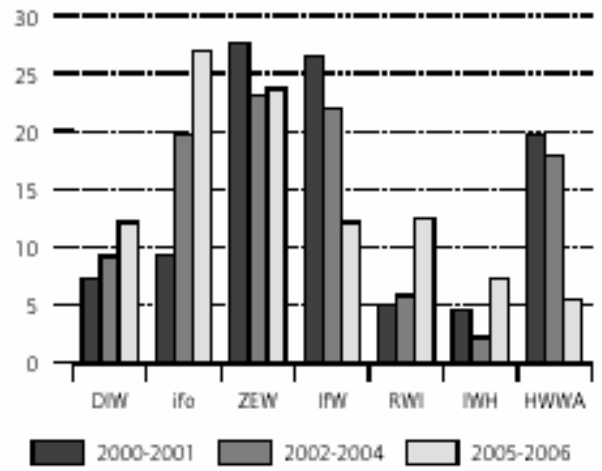

Sources: Annual reports of the institutes; calculations of DIW Berlin.

DIW Berlin 2007 
Fig. 11

Number of SSCI publications weighted with impact factors

Market share in \%

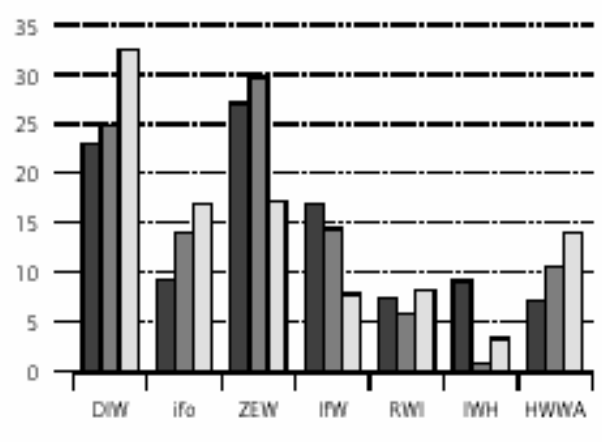

$\square$ 2000-2001 2002-2004 $\square$ 2005-2006

Sources: Annual reports of the institutes; calculations of DIW Berlin.

DIW Berlin 2007

Fig. 12

Number of SSCI publications weighted with impact factors per full-time equivalent Market share in \%

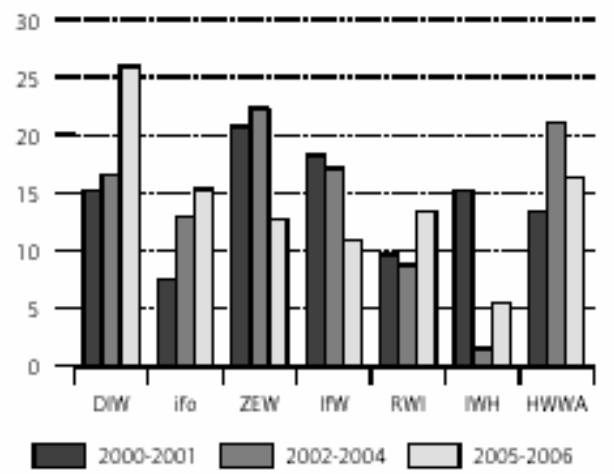

Sources: Annual reports of the institutes; calculations of DIW Berlin.

DIW Berlin 2007 
Fig. 13

Institution-weighted numbers of pages

in SSCI publications weighted with

impact factors

Market share in \%

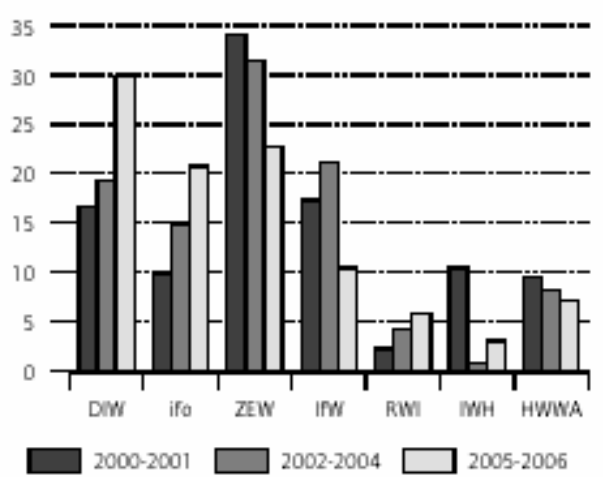

Sources: Annual reports of the institutes; calculations of DIW Berlin.

DIW Berlin 2007

Fig. 14

Institution-weighted numbers of pages in SSCI publications weighted with impact factors per full-time equivalent Market share in \%

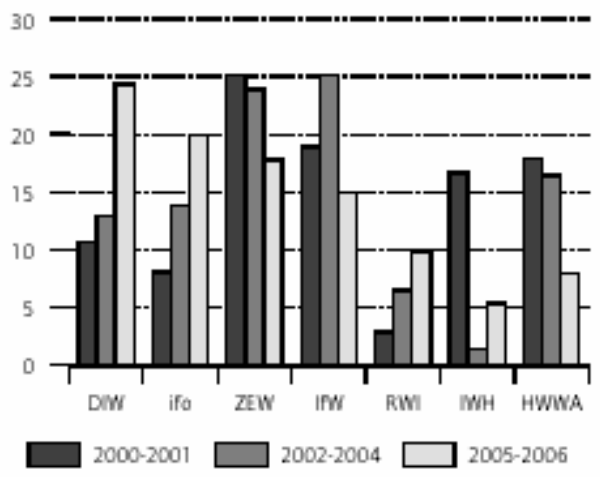

Sources: Annual reports of the institutes; calculations of DIW Berlin.

DIW Berlin 2007 
Fig. 15

Distribution of publications 2004

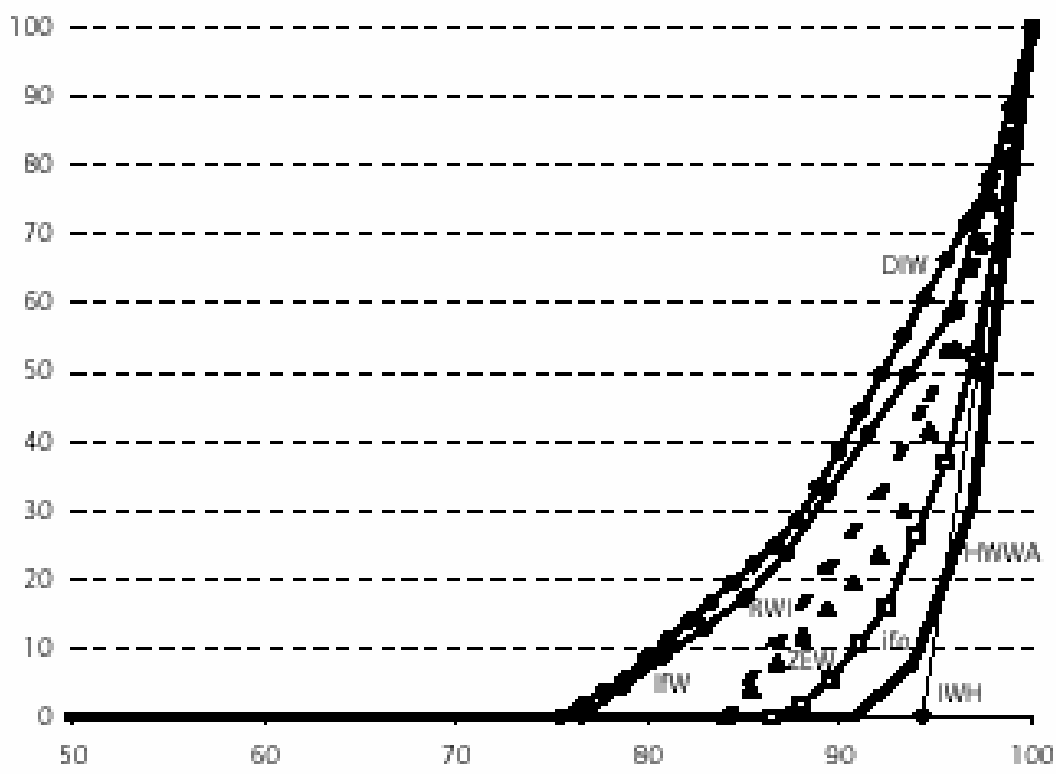

Scientists in \%

Sources: Annual reports of the institutes; calculations of DIW Berlin.

DIW Berlin 2007

Fig. 16

Distribution of publications 2006

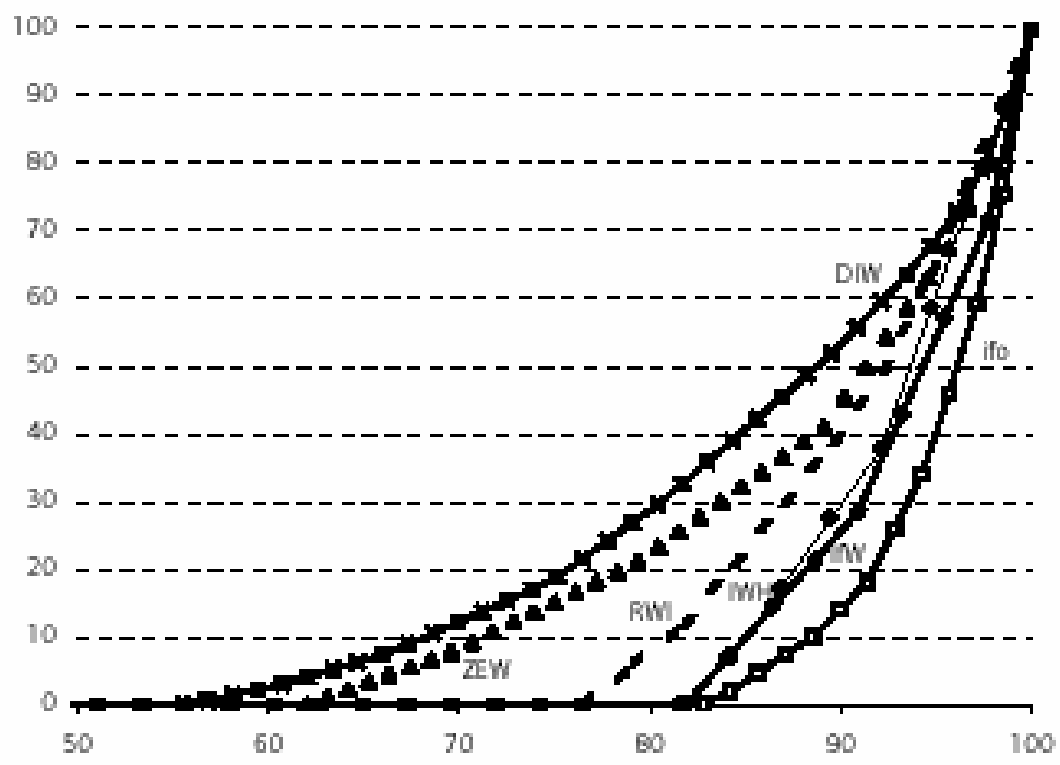

Scientists in \%

Sources: Annual reports of the institutes; calculations of DIW Berlin. DIW Berlin 2007 